\title{
Sistem Informasi Monitoring Penjualan Dan Prediksi Stok Barang Kios Pulsa Menggunakan Moving Average Berbasis Website
}

\author{
Ahmad Fauzi ${ }^{1}$, Prof.Dr.Iskandar Fitri ${ }^{2}$, Benrahman ${ }^{3}$ \\ ${ }^{1,2,3}$ Universitas Nasional, Jl. Sawo Manila No.61, RW.7, Pejaten Bar., Kec. Ps. Minggu, Kota \\ Jakarta Selatan,tlpn/fax (021)7806700 \\ e-mail:*1 fauzi12922@gmail.com, ${ }^{2}$ Tektel2001@yahoo.com, ${ }^{3}$ Ben.rahman@gmail.com
}

\begin{abstract}
Abstrak
Kios pulsa adalah toko kecil yang beredar untuk menjual berbagai macam produk kebutuhan handphone seperti aksesoris, perangkat charger, usb, headset, terutama paket data seluler. Pada transaksi jual beli pulsa yang ada pada kios memiliki alur dimana pelanggan harus mencatatkan nomor yang akan diisi pulsa, nominal, kemudian penjual akan memasukkan pulsa sesuai permintaan pelanggan, jika pulsa berhasil masuk maka pelanggan membayar dan pembeli mencatatkan harga pada pembukuan yang sama dengan pembukuan nomor serta nominal pelanggan.Transaksi tersebut tentu membutuhkan sistem yang dapat menyederhanakan proses sehingga pengolahan data dapat lebih cepat dan dokumentasi lebih aman dibandingkan dokumentasi pembukuan. Sistem informasi monitoring penjualan dan stok barang kios pulsa berbasis website dapat mengolah data mulai dari data transaksi, prediksi stok barang, hingga menghasilkan informasi yang memudahkan penjual dalam monitoring (memantau) laporan harian tanpa harus membuka dokumen-dokumen transaksi yang membutuhkan waktu lebih lama serta dokumentasi yang bersifat media cetak Sistem informasi monitoring berbasis website dibangun menggunakan bahasa program PHP dengan framework codeigniter dan manajemen database MySQL. Sistem informasi monitoring berbasis website dapat melakukan olah data secara virtual dimana pembeli memasukkan data pembelian, dari data tersebut akan disimpan dalam sistem dan penjual dapat melakukan olah data langsung dari sistem berbasis website tanpa terbatas ruang dan waktu. Data yang tersimpan dapat dilihat kapanpun dan dimanapun. Aplikasi prediksi stok barang dapat membantu pemilik kios dalam mengambil keputusan terhadap jumlah barang optimal yang akan dipesan ke supplier.
\end{abstract}

Kata kunci: Monitoring. Website, PHP, Moving Average, MySQL, Sistem informasi, Penjualan

\begin{abstract}
Pulse shop is a small shop that sells a variety of mobile phone product needs such as accessories, charger devices, usb, headsets, especially cellular data packages. In buying and selling pulses at the store with a flow where the customer must record the number that will top up the credit, then the seller will enter the credit according to the customer's request, if the credit is successful, the customer pays and the buyer records the price in the same bookkeeping as the customer number. Such transactions certainly require a system that can simplify the process so that data processing can be faster and documentation is safer than book-keeping documentation. The website-based information system for monitoring sales and stock of goods, a website-based credit kiosk, can process data ranging from transaction data, stock data, to producing information that makes it easier for sellers to monitor reports without having to open transaction documents that require longer time and documentation that is media in nature print The website-
\end{abstract}


based monitoring information system is built using the PHP programming language with a codeigniter framework and MySQL database management. The website-based monitoring information system can process data virtually where the buyer enters purchase data, from which the data will be stored in the system and the seller can process data directly from the websitebased system without being limited by space and time. Stored data can be seen anytime and anywhere. The app predicts the stock of goods can assist stallholders in making decisions about the optimal number of items to be ordered to suppliers.

Keywords: Monitoring.Moving Average, Website, PHP, MySQL, Information systems, Sales.

\section{PENDAHULUAN}

Jona Pulsa adalah kios pulsa yang berada di Jl. Kemang Utara IX No.26, RT.3/RW.4, Bangka, Kec. Mampang Prpt., Kota Jakarta Selatan. Kios pulsa adalah toko kecil yang beredar untuk menjual berbagai macam produk kebutuhan handphone seperti aksesoris, perangkat charger, usb, headset, terutama paket data seluler. Paket data seluler adalah kebutuhan setiap pengguna device untuk mendapatkan layanan internet dimana pengguna dapat menelusuri berbagai hal. Paket data seluler memiliki banyak varian, mulai dari varian operator, varian kapasitas kuota, dan varian harga. Selain paket data, adapun varian pulsa isi ulang yang ada di kios untuk memenuhi kebutuhan atau pembelian paket data seluler jika pengguna ingin melakukan isi ulang paket data dengan provider yang sedang digunakan.

Pada transaksi jual beli pulsa yang ada pada kios memiliki alur dimana pelanggan harus mencatatkan nomor yang akan diisi pulsa, nominal, kemudian penjual akan memasukkan pulsa sesuai permintaan pelanggan, jika pulsa berhasil masuk maka pelanggan membayar dan pembeli mencatatkan harga pada pembukuan yang sama dengan pembukuan nomor serta nominal pelanggan. Alur transaksi tersebut berdampak pada durasi dengan waktu yang tergolong tidak sebentar dan pendataan yang tidak mudah dikelola karena mengharuskan penjualan membuka kembali buku catatan laporan penjualan untuk menganalisa data yang ada. Proses transaksi tersebut tentu membutuhkan sistem yang dapat menyederhanakan proses sehingga pengolahan data dapat lebih cepat dan dokumentasi lebih aman dibandingkan dokumentasi pembukuan.

Sistem informasi adalah sebuah rangkaian prosedur normal dimana data dikumpulkan, diproses menjadi informasi dan didistribusikan kepada para pengguna (Lasminiasih, P, Akbar, Andriansyah, \& Utomo, 2016). Sistem informasi monitoring penjualan dan stok barang kios pulsa berbasis website dapat mengolah data mulai dari data transaksi, prediksi stok barang, hingga menghasilkan informasi yang memudahkan penjual dalam monitoring (memantau) laporan harian tanpa harus membuka dokumen-dokumen transaksi yang membutuhkan waktu lebih lama serta dokumentasi yang bersifat media cetak. Sistem informasi monitoring berbasis website dapat melakukan olah data secara virtual dimana pembeli memasukkan data pembelian, dari data tersebut akan disimpan dalam sistem dan penjual dapat melakukan olah data langsung dari sistem berbasis website tanpa terbatas ruang dan waktu. Data yang tersimpan dapat dilihat kapanpun dan dimanapun.

Sistem informasi monitoring berbasis website dibangun menggunakan bahasa program PHP dengan framework codeigniter dan manajemen database MySQL yang bersifat umum sehingga memudahkan pengembangan sistem. Dalam sistem informasi monitoring akan diberikan hak akses kepada penjual sebagai pengolah data dan pemilik dengan hak akses monitoring data pada kios. Pada pengembangan sistem informasi monitoring berbasis website diharapkan memudahkan pengolahan data dan integrasi pengguna tanpa ada batasan seperti pada pengolahan data manual dengan sistem dokumentasi pembukuan. Dan untuk memprediksi

Ahmad, et.,al (Sistem Informasi Monitoring Penjualan Dan Prediksi Stok Barang Kios Pulsa Menggunakan Moving Average Berbasis Website) 
harga beli dari bahan baku tersebut menggunakan metode moving average. Peramalan rataan bergerak (moving average) menggunakan sejumlah data aktual masa lalu untuk menghasilkan peramalan. Secara matematis, rataan bergerak sederhana.

Berdasarkan permasalahan diatas maka penulis akan melakukan penelitian dengan judul "Sistem Informasi Monitoring Penjualan Dan Prediksi Stok Barang Kios Pulsa Menggunakan Moving Average Berbasis Website" untuk memudahkan pengolahan data transaksi pada kios pulsa (Jona Pulsa).

\section{METODE PENELITIAN}

Penelitian ini dilaksanakan dengan teknik interview untuk mengumpulkan data yang diperlukan serta melakukan kajian pustaka untuk menyokong dalam pengambilan hasil penelitian.

Tahapan dalam penelitian dapat diuraikan seperti berikut ini:

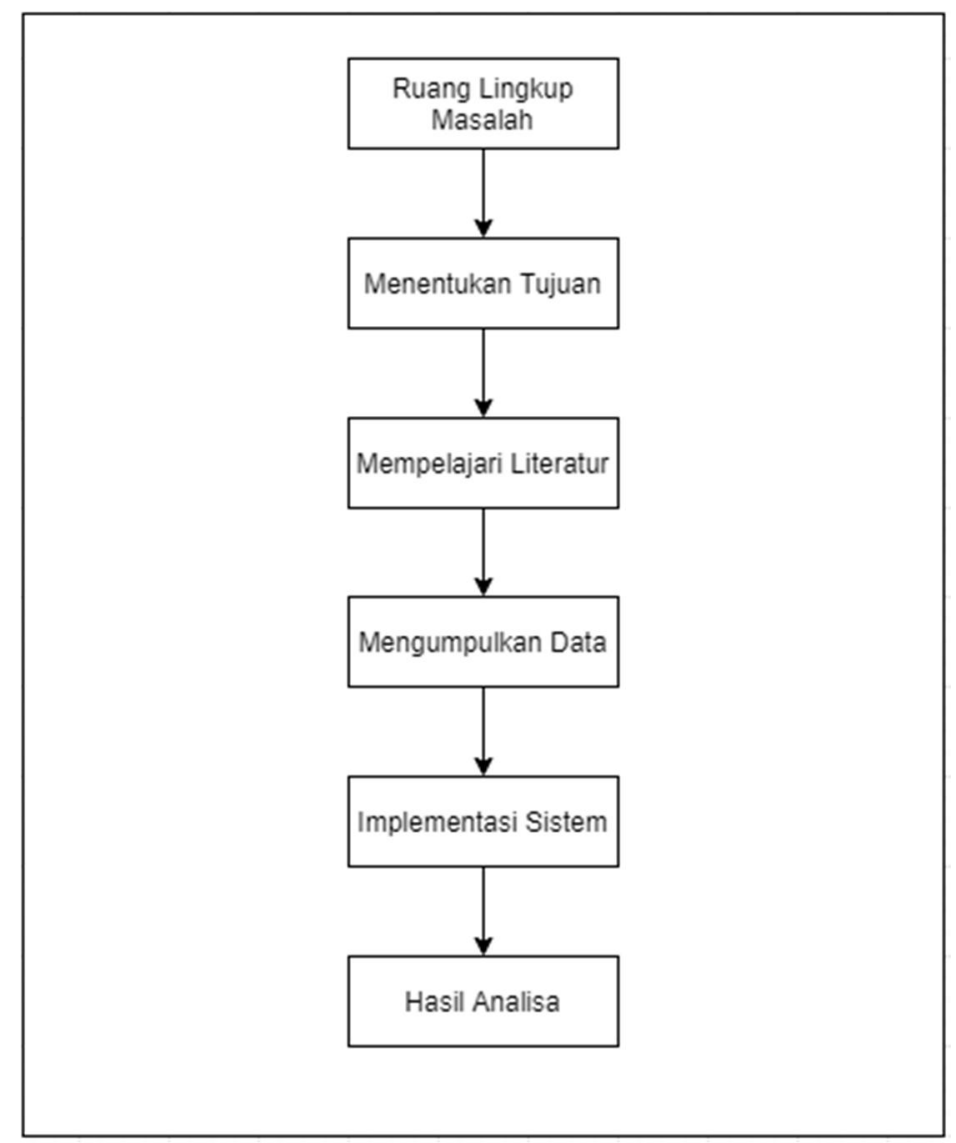

Gambar 1. Alur Proses Penelitian

Ruang Lingkup Masalah

Pada penelitian yang dilakukan ini memiliki ruang lingkup seperti berikut:

Sistem ditujukan untuk penjual di kios pulsa - Jona Pulsa.

Sistem yang akan dibangun berbasis website.

Data yang digunakan adalah data item yang dijual.

Ahmad, et.,al (Sistem Informasi Monitoring Penjualan Dan Prediksi Stok Barang Kios Pulsa Menggunakan Moving Average Berbasis Website) 
Menentukan Tujuan

Dari masalah yang dipahami, maka sudah ditentukan tujuan yang harus dicapai dalam penelitian ini. Tujuan ini menilai target yang dicapai, khususnya yang dapat menanggulangi permasalahan yang ada dalam hal monitoring transaksi di Jona Pulsa.

\section{Mempelajari Literatur}

Agar mencapai tujuan, maka dipelajari sejumlah literatur yang dapat digunakan. Kemudian literatur yang telah dipelajari itu dipilih agar dapat ditentukan literatur apa saja yang akan digunakan dalam penelitian. Literatur diambil dari internet, yang berupa tulisan dan jurnal ilmiah tentang Sistem Informasi Monitoring dari beberapa buku yang mendukung penelitian.

\section{Mengumpulkan Data}

Untuk pengumpulan data dilaksanakan wawancara yang bertujuan guna mendapatkan informasi atau data yang dibutuhkan. Kemudian dilakukan observasi yaitu pengamatan secara langsung ditempat riset sehingga persoalan yang ada bisa diketahui secara jelas. Selain itu juga mencari sumber bacaan menggunakan beberapa buku yang dapat menunjang dalam penelitian ini.

Implementasi Sistem

Implementasi sistem ini berguna agar mempermudah pada saat pembuktian hasil analisa yang sebelumnya dilakukan.

Analisa Hasil

Analisa hasil dari sistem yang dibangun dilakukan untuk menemukan hasil implementasi sistem yang digunakan untuk informasi monitoring di Jona Pulsa.

\subsection{Sistem Informasi}

Sistem informasi merupakan kombinasi teratur dari orang-orang, perangkat keras (hardware), perangkat lunak (software), jaringan komunikasi, dan sumber daya data yang mengumpulkan, mengubah, dan menyebarkan informasi dalam sebuah organisasi (Firman, Wowor, \& Najoan, 2016). Adapun pengertian lain sistem informasi adalah suatu sistem di dalam suatu organisasi yang mempertemukan kebutuhan pengolahan data transaksi harian, mendukung operasi, bersifat manajerial dan kegiatan strategi dari suatu organisasi serta menyediakan pihak luar tertentu dengan laporan-laporan yang diperlukan.

\subsection{Sistem Monitoring}

Sistem adalah suatu jaringan kerja dari prosedur-prosedur yang saling berhubungan, berkumpul bersama-sama untuk melakukan suatu kegiatan atau untuk menyelesaikan suatu sasaran tertentu (Ramayasa \& Ketut Surya Arnawa, 2015). Sistem monitoring merupakan suatu proses untuk mengumpulkan data dari berbagai sumber daya. Biasanya data yang dikumpulkan merupakan data yang realtime.

\subsection{Website}

Website adalah kumpulan halaman-halaman yang berasal dari file-file berisi bahasa pemrograman yang saling berhubungan digunakan untuk menampilkan informasi, gambar bergerak dan tidak bergerak, suara dan atau gabungan dari semuanya itu baik yang bersifat statis maupun dinamis (Hendini, PEMODELAN UML SISTEM INFORMASI MONITORING PENJUALAN DAN STOK BARANG (STUDI KASUS: DISTRO ZHEZHA PONTIANAK), 2016).

Ahmad, et.,al (Sistem Informasi Monitoring Penjualan Dan Prediksi Stok Barang Kios Pulsa Menggunakan Moving Average Berbasis Website) 


\subsubsection{PHP}

PHP merupakan script untuk pemrograman script web server-side, script yang membuat dokumen HTML secara on the fly, maksudnya dokumen HTML yang dihasilkan dari suatu aplikasi bukan dokumen HTML yang dibuat dengan menggunakan editor teks atau editor HTML (Sovia \& Febio, 2017). PHP/FI merupakan nama awal dari PHP. PHP adalah Personal Home Page, FI adalah Form Interface. Dibuat pertama kali oleh Rasmus Lerdoff. PHP, awalnya merupakan program yang dikhususkan untuk menerima input melalui form yang ditampilkan dalam browser web. Software ini disebarkan dan dilisensikan sebagai perangkat lunak Open Source. PHP secara resmi merupakan kependekan dari PHP Hypertext Preprocessor, merupakan bahasa script server-side yang disisipkan pada HTML. Berikut adalah contoh yang umum digunakan untuk menjelaskan tentang PHP sebagai script yang disisipkan dalam dokumen HTML:

\begin{tabular}{l}
\hline <html $>$ \\
<head $><$ title $>$ Contoh $</$ title $></$ head $>$ \\
< body> \\
<?php echo "Tulisan ini dibuat dengan \\
script PHP"; ?> \\
</body> \\
</html>
\end{tabular}

\subsubsection{Database (MySQL)}

Database secara sederhana, dapat kita sebut sebagai gudang data (Sovia \& Febio, 2017). secara teori, database adalah kumpulan data atau informasi yang kompleks, data-data tersebut disusun menjadi beberapa kelompok dengan tipe data yang sejenis disebut table/entity), di mana setiap datanya dapat saling berhubungan satu sama lain atau dapat berdiri sendiri, sehingga mudah diakses. MySQL merupakan database yang awalnya hanya berjalan pada sistem Unix dan Linux. Seiring berjalannya waktu dan banyaknya peminat yang menggunakan database ini, MySQL merilis versi yang dapat diinstal pada hampir semua platform, termasuk Windows.

\subsection{Moving Average}

Peramalan rataan bergerak (moving average) menggunakan sejumlah data aktual masa lalu untuk menghasilkan peramalan. Secara matematis, rataan bergerak sederhana (merupakan prediksi permintaan periode mendatang) dinyatakan sebagai berikut:

Dimana:

$$
M A=\frac{\sum x}{n}
$$

$$
\begin{array}{ll}
\text { MA } & =\text { Moving Average } \\
\sum_{\mathrm{n}} & =\text { Jumlah data periode waktu } \\
& =\text { Jumlah periode rata-rata bergerak }
\end{array}
$$

Implementasi sistem informasi monitoring yang akan dibangun memiliki perancangan seperti berikut:

\section{Use Case Diagram}

Sistem yang akan dibangun memiliki 2 aktor yaitu admin dan pemilik. Admin memiliki hak akses untuk login, kelola data pengguna dimana pengguna yang dapat mengaksis sistem dapat admin kelola, kelola data barang yang merupakan pengolahan data barang di kios, kelola 
data stok dimana admin mengolah data stok barang tersedia atau terjual, kelola transaksi admin dapat melayani atau melakukan transaksi dengan pelanggan dimana data kebutuhan pelanggan didokumentasikan pada sistem oleh admin dan lihat laporan. Pemilik memiliki hak akses untuk melihat login dan laporan toko yang dikelola oleh admin. Berikut adalah use case diagram untuk sistem yang akan dibangun.

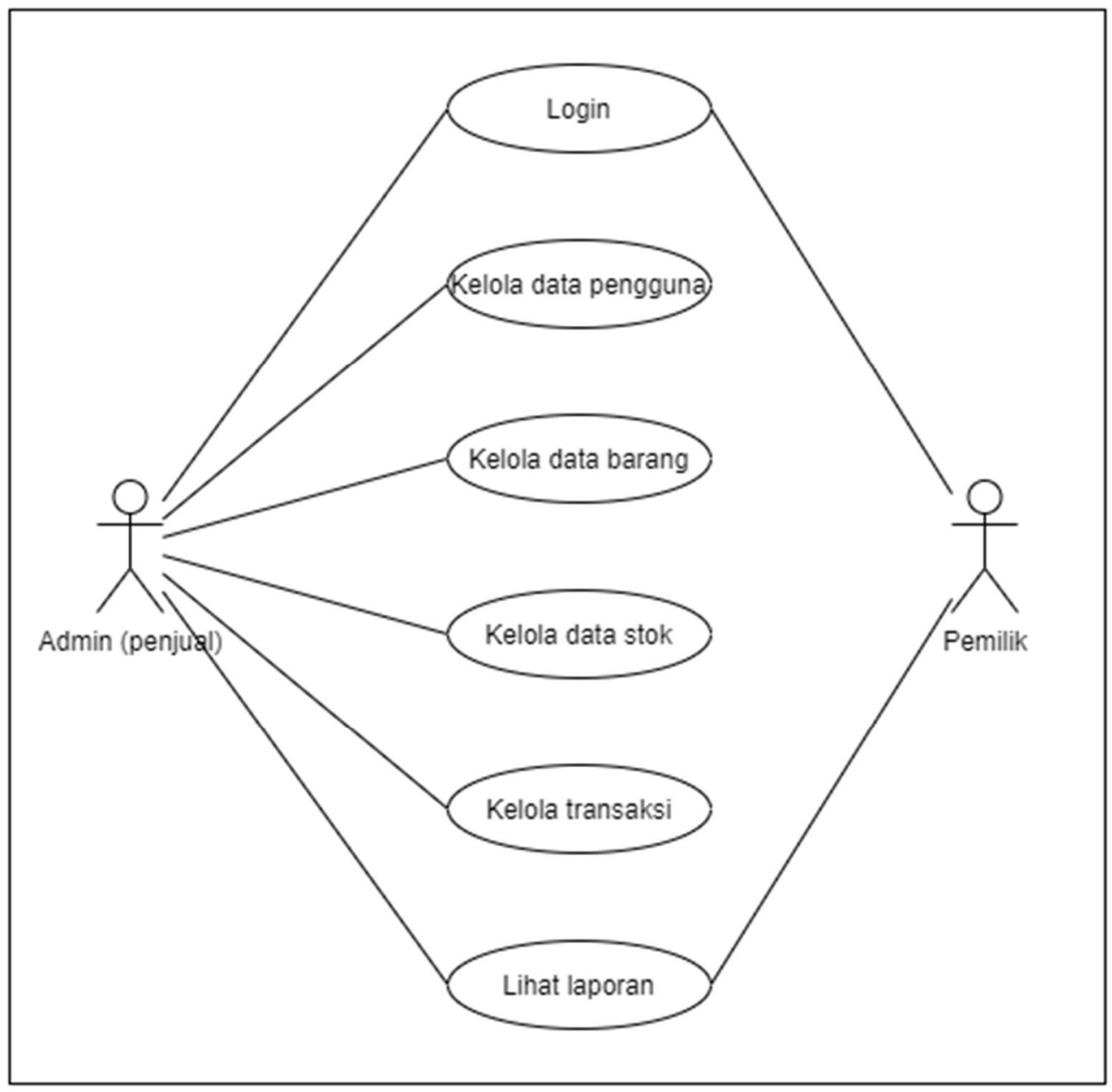

Gambar 2. Use Case Diagram

Activity Diagram

Activity diagram dibuat untuk merancang aktifitas pengguna dengan sistem seperti berikut: Activity Diagram Login

\section{HASIL DAN PEMBAHASAN}

Implementasi Program (Isinya Screenshot Program)

Implementasi Sistem Admin 
1. Halaman Login

Halaman login merupakan halaman yang berfungsi untuk admin dalam melakukan login, admin terlebih dahulu memasukkan username dan password yang benar untuk dapat mengakses menu menu yang terdapat di dalamnya.

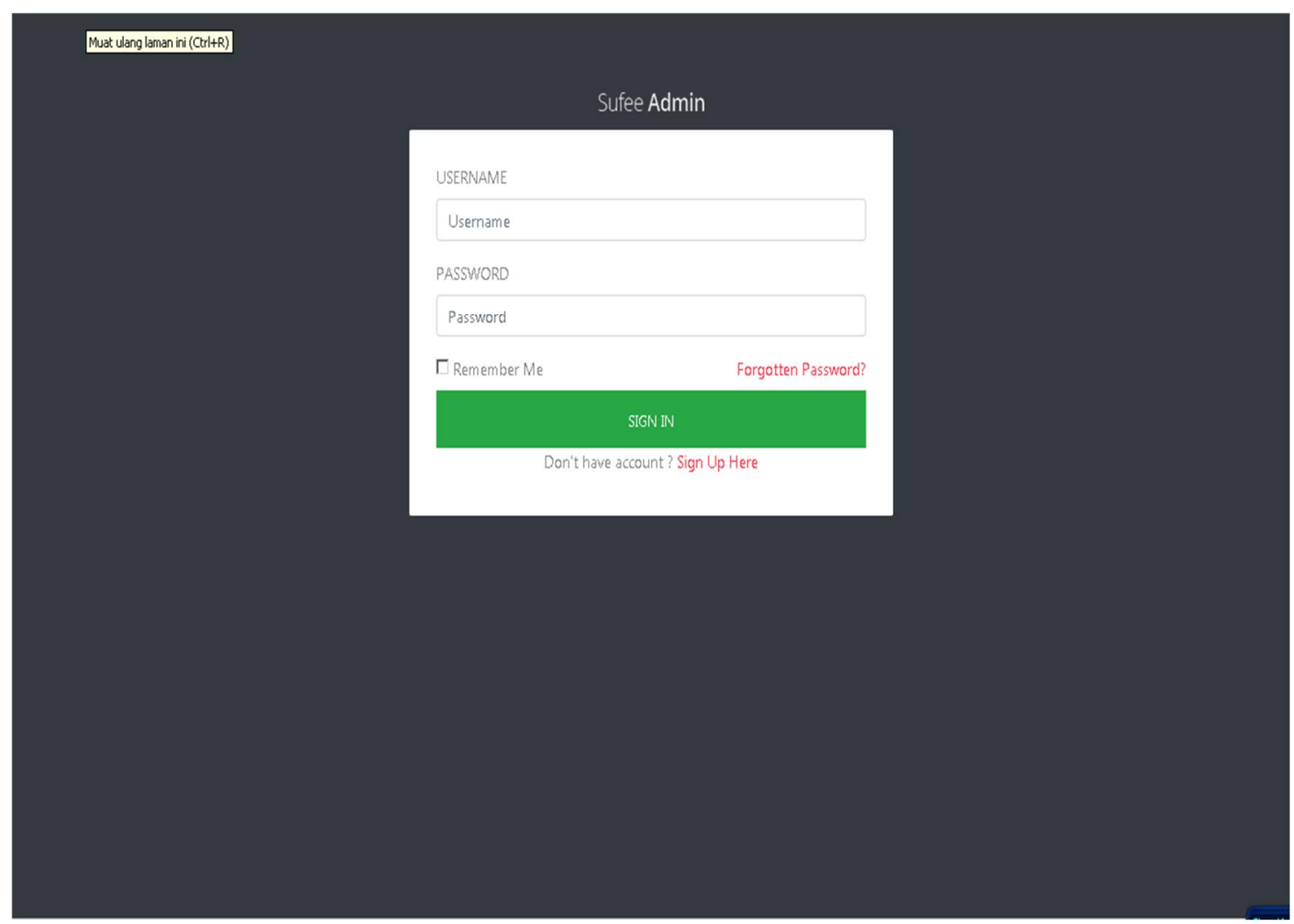

Gambar 3. Halaman Login

2. Halaman Dashboard

Halaman Dashboard adalah halaman awal setelah login atau menu utama

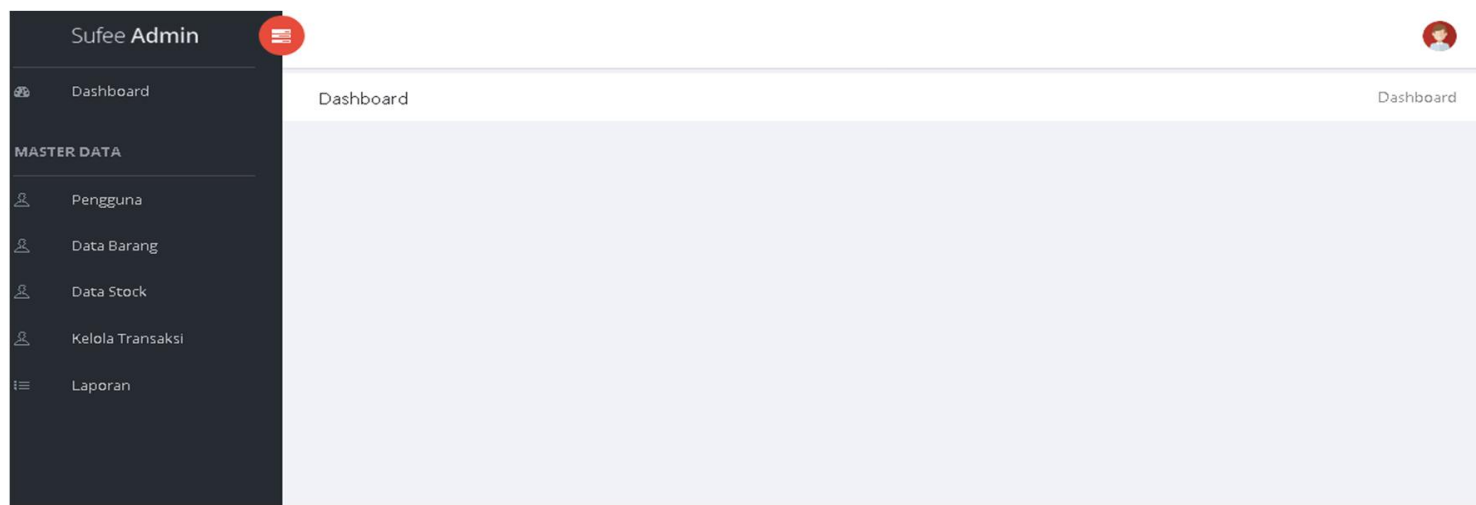

Gambar 4. Dashboard

\section{Halaman Pengguna}

Halaman pengguna adalah halaman untuk melihat list pengguna

Ahmad, et.,al (Sistem Informasi Monitoring Penjualan Dan Prediksi Stok Barang Kios Pulsa Menggunakan Moving Average Berbasis Website) 
Jatisi

ISSN 2407-4322

Vol. 8, No. 1, Maret 2021, Hal. 26-40

E- ISSN 2503-2933
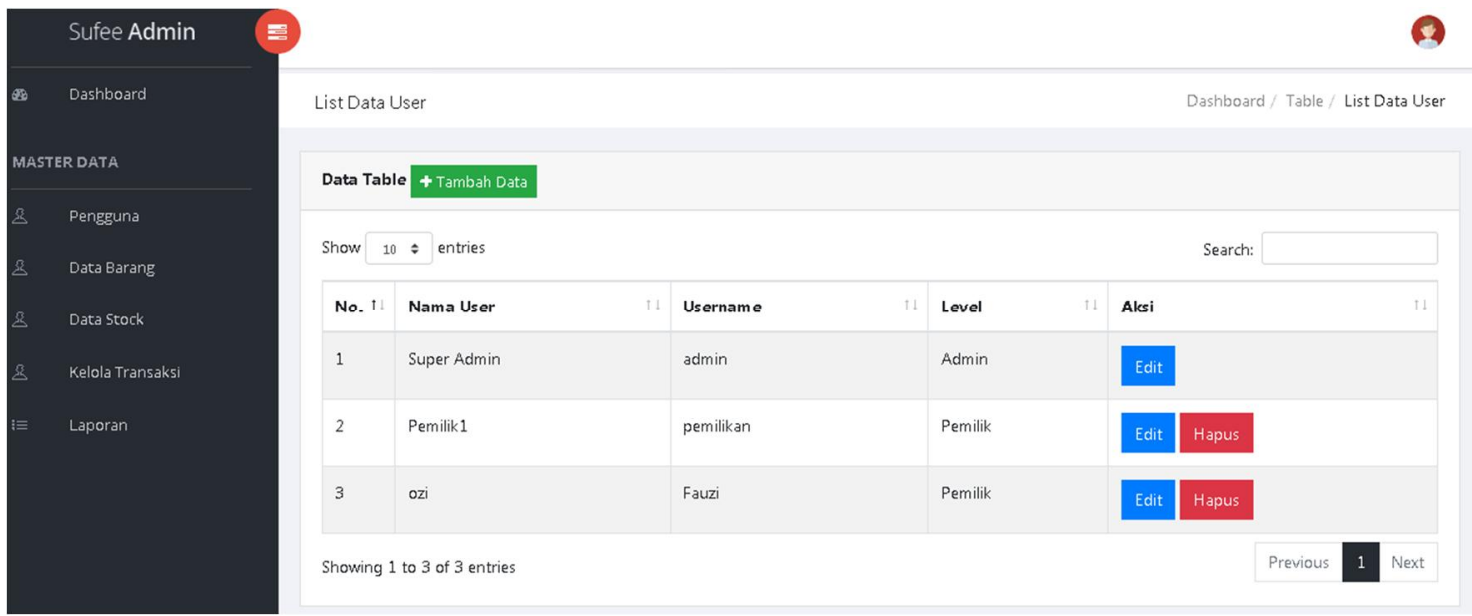

Gambar 5. Halaman pengguna
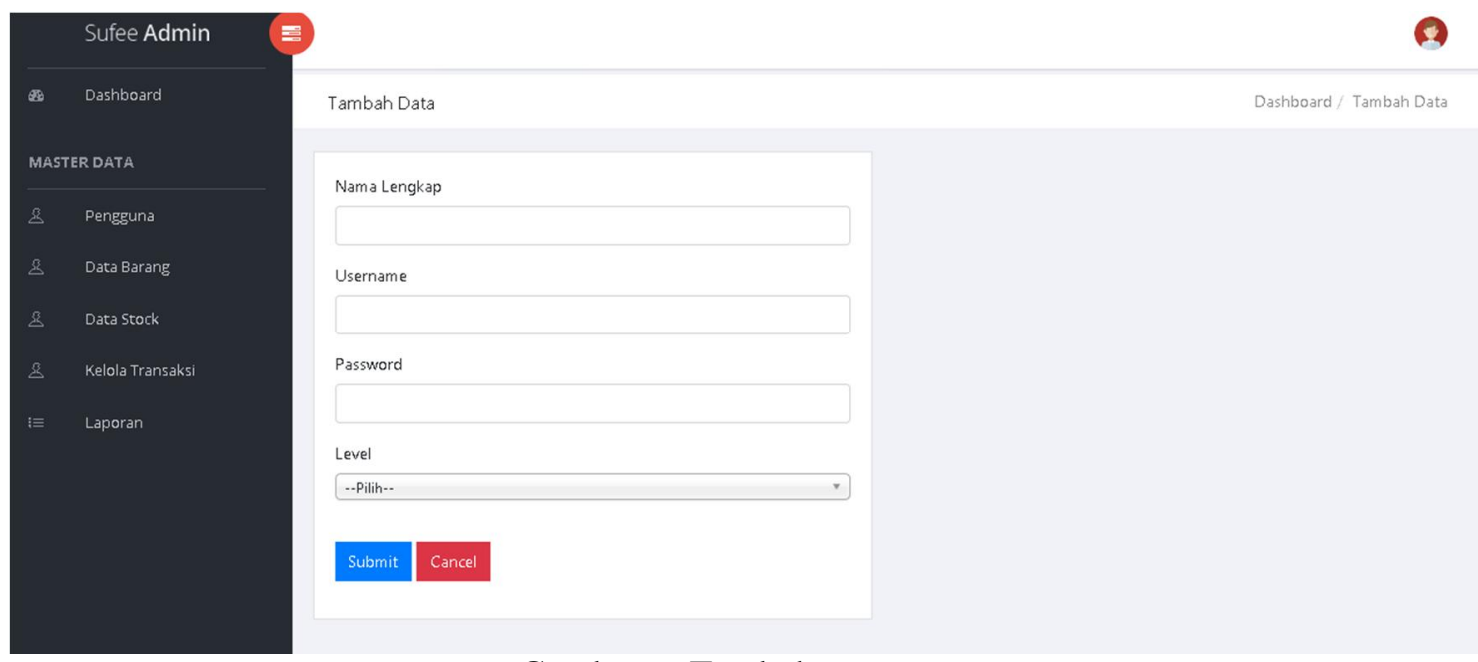

Gambar 6. Tambah pengguna
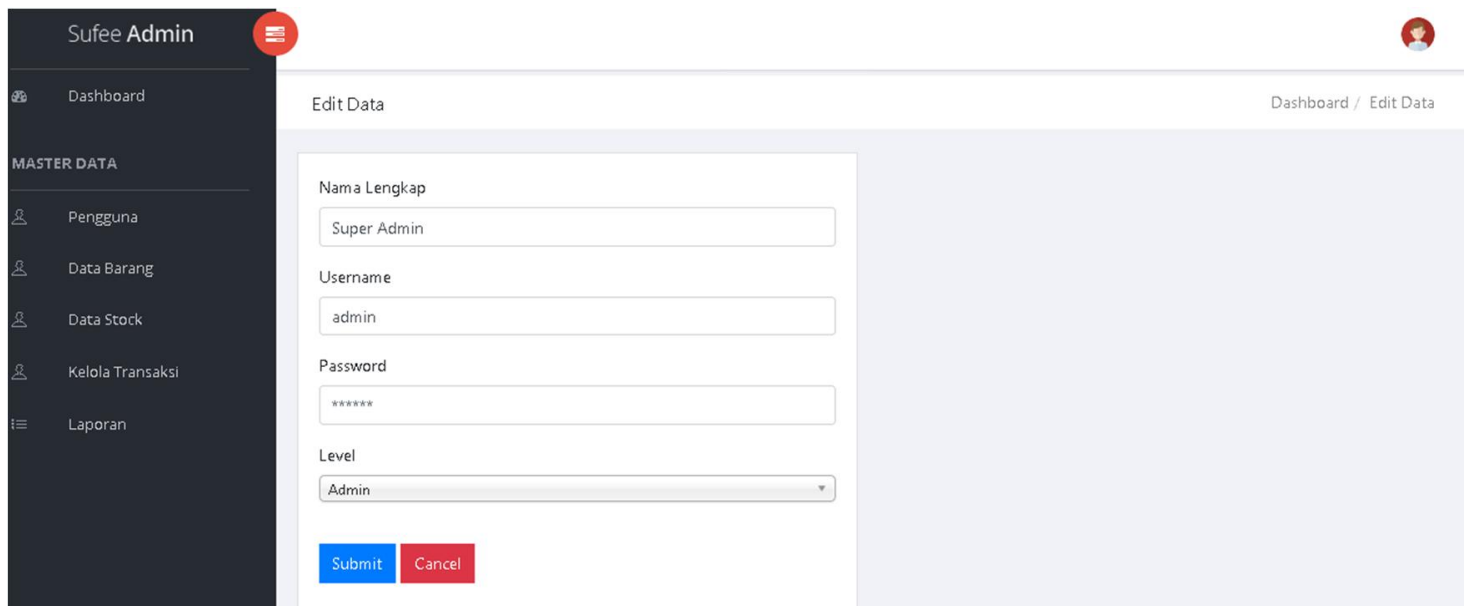

Gambar 7. Edit Pengguna

Ahmad, et.,al (Sistem Informasi Monitoring Penjualan Dan Prediksi Stok Barang Kios Pulsa Menggunakan Moving Average Berbasis Website) 
4. Halaman Data Barang

Halaman data barang adalah halaman yang menampilkan data barang yang tersedia

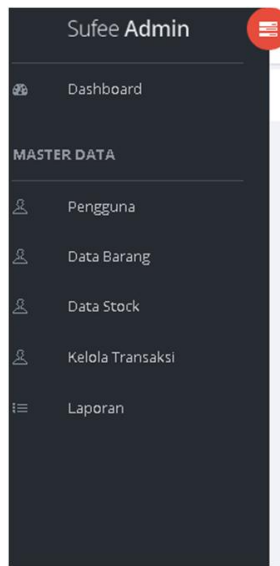

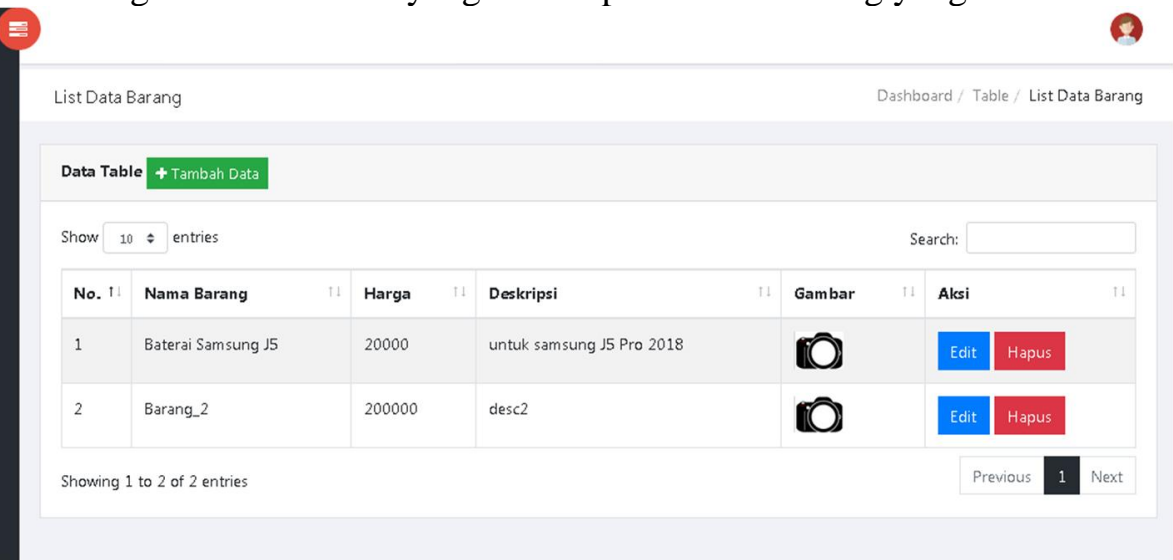

Gambar 8. Halaman data barang

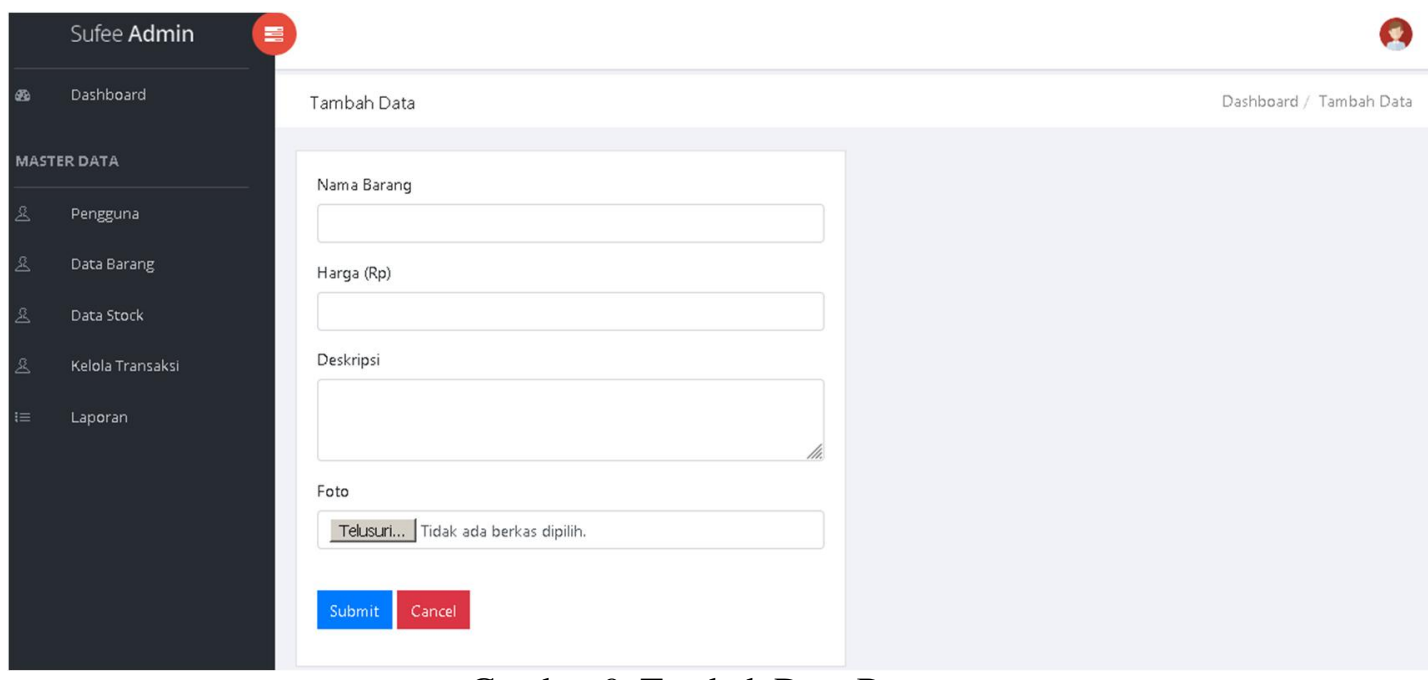

Gambar 9. Tambah Data Barang 
Jatisi

ISSN 2407-4322

Vol. 8, No. 1, Maret 2021, Hal. 26-40

E- ISSN 2503-2933
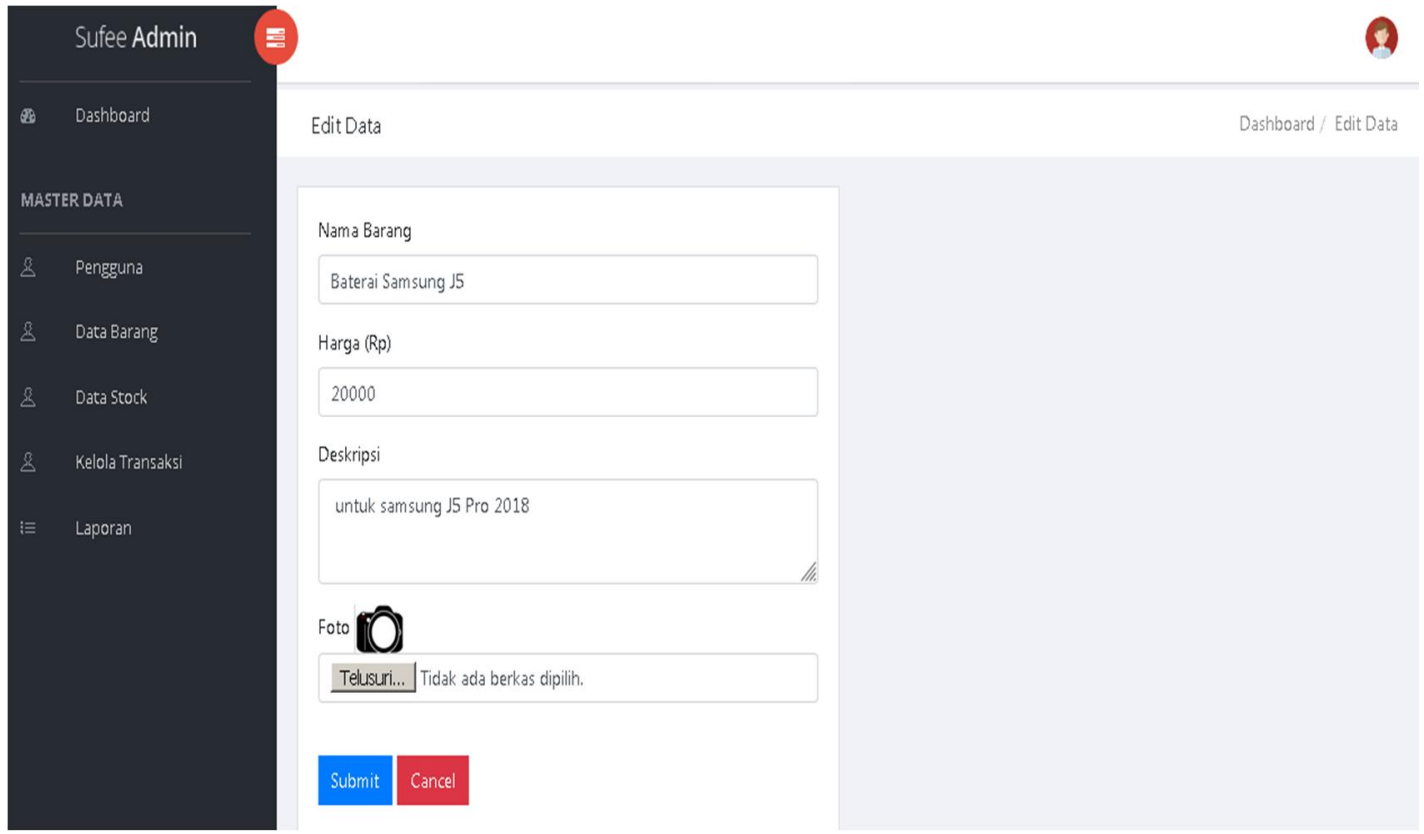

Gambar 10. Edit Data Barang

5. Halaman Data Stock

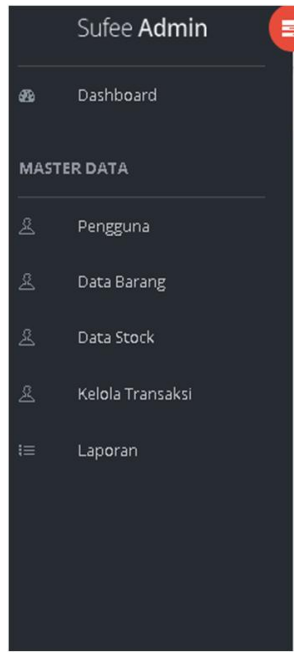

\begin{tabular}{|c|c|c|c|c|c|c|}
\hline \multicolumn{4}{|c|}{ List Data Stock } & \multicolumn{3}{|c|}{ Dashboard / Table / List Data Stock } \\
\hline \multicolumn{7}{|c|}{ Data Stock } \\
\hline \multicolumn{4}{|c|}{ Show $10 *$ entries } & \multicolumn{2}{|r|}{ Search: } & \\
\hline No. 1 & Nama Barang & 11 & Stock & 11 & Alsi & 11 \\
\hline 1 & Baterai Samsung 15 & & 10 & & Edit & \\
\hline 2 & Barang_2 & & 3 & & Edit & \\
\hline 3 & $a b c$ & & & & Edit & \\
\hline \multicolumn{4}{|c|}{ Showing 1 to 3 of 3 entries } & & & Previous \\
\hline
\end{tabular}

Gambar 1. Stock Data Barang

Halaman stock berfungsi untuk mencatat stock barang yang tersedia 

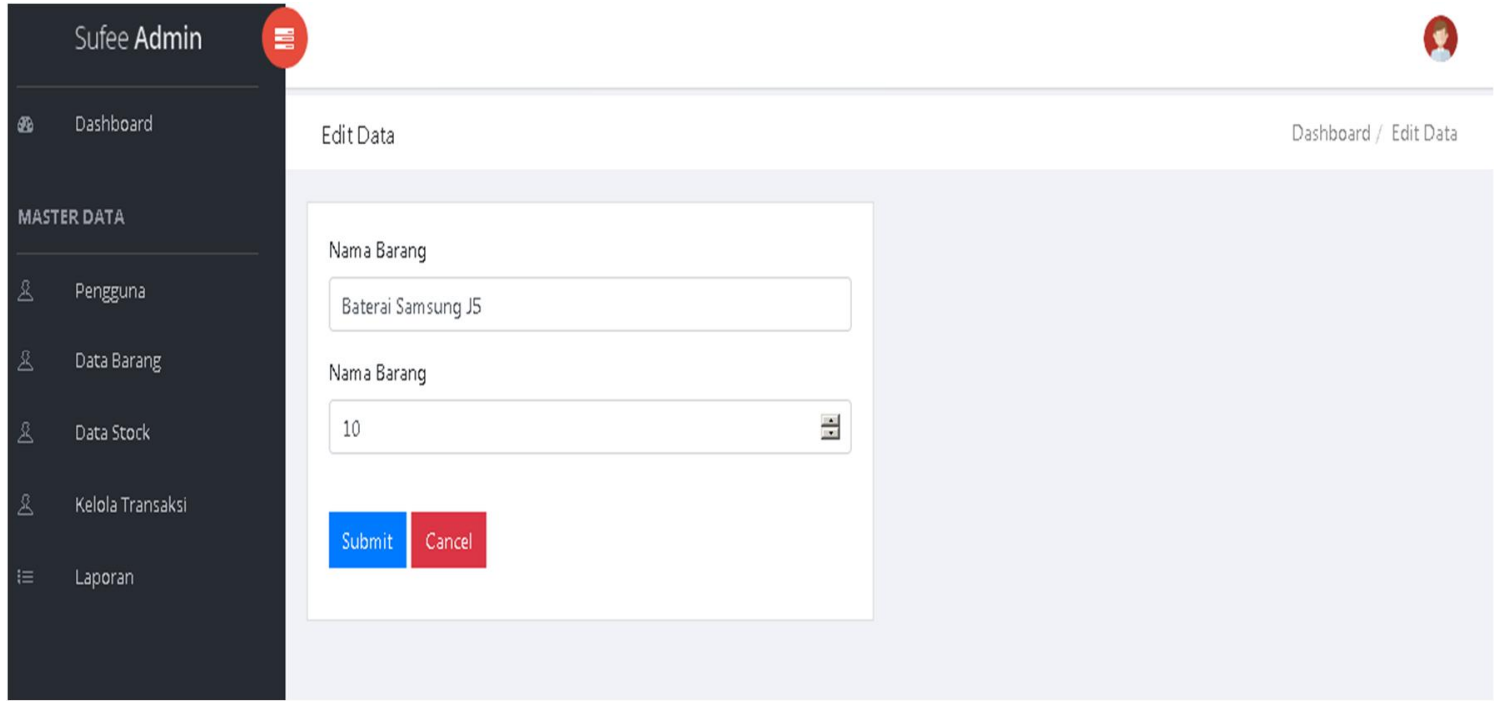

\section{Gambar 12. Edit Stock Barang}

6. Halaman Transaksi

Halaman Transaksi berfungsi untuk melihat transaksi yang sudah di lakukan

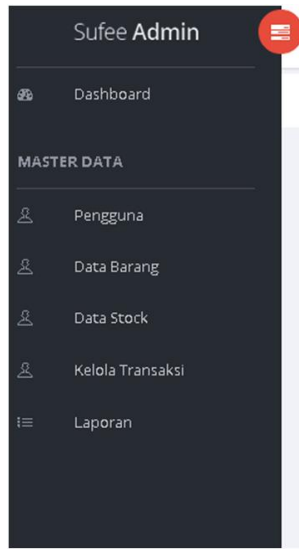

List Data transaks

Data Table

Show $10 *$ entries

Search:

No. It No Transaksi

Tanggal Transaksi

Aksi

$120200101001 \quad$ 2020-11-06

\begin{tabular}{|l|l|}
\hline 20200101002 & $2020-11-0$
\end{tabular}

Gambar 13. Data Transaksi 


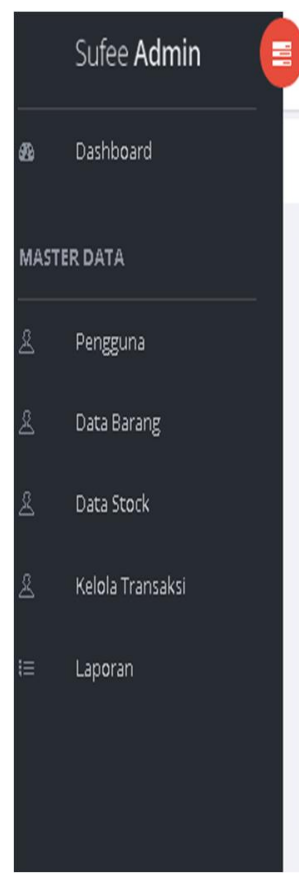

\begin{tabular}{|c|c|c|c|c|c|c|c|c|c|c|}
\hline \multicolumn{4}{|l|}{ EditData } & & & & & & \multicolumn{2}{|c|}{ Dashboard / Edit Data } \\
\hline \multicolumn{11}{|c|}{ Data Table } \\
\hline Show 1 & $0 \leqslant$ entries & & & & & \multicolumn{5}{|c|}{ Search: } \\
\hline No. 1 & Items & 11 & Gambar & 11 & Qty & $1 !$ & Harga & it & SubTotal & 11 \\
\hline 1 & Barang_2 & & & & 2 & & $\operatorname{Rp} 200000$ & & $\operatorname{Rp} 400000$ & \\
\hline 2 & Baterai Samsung 15 & & & & 1 & & Rp 20000 & & Rp 20000 & \\
\hline \multicolumn{4}{|c|}{ Showing 1 to 2 of 2 entries } & & & & & & Previous & Next \\
\hline
\end{tabular}

Gambar 14. Lihat Data Transaksi

\section{Halaman Laporan}

Halaman laporan berfungsi untuk menampilkan laporan dari penjualan

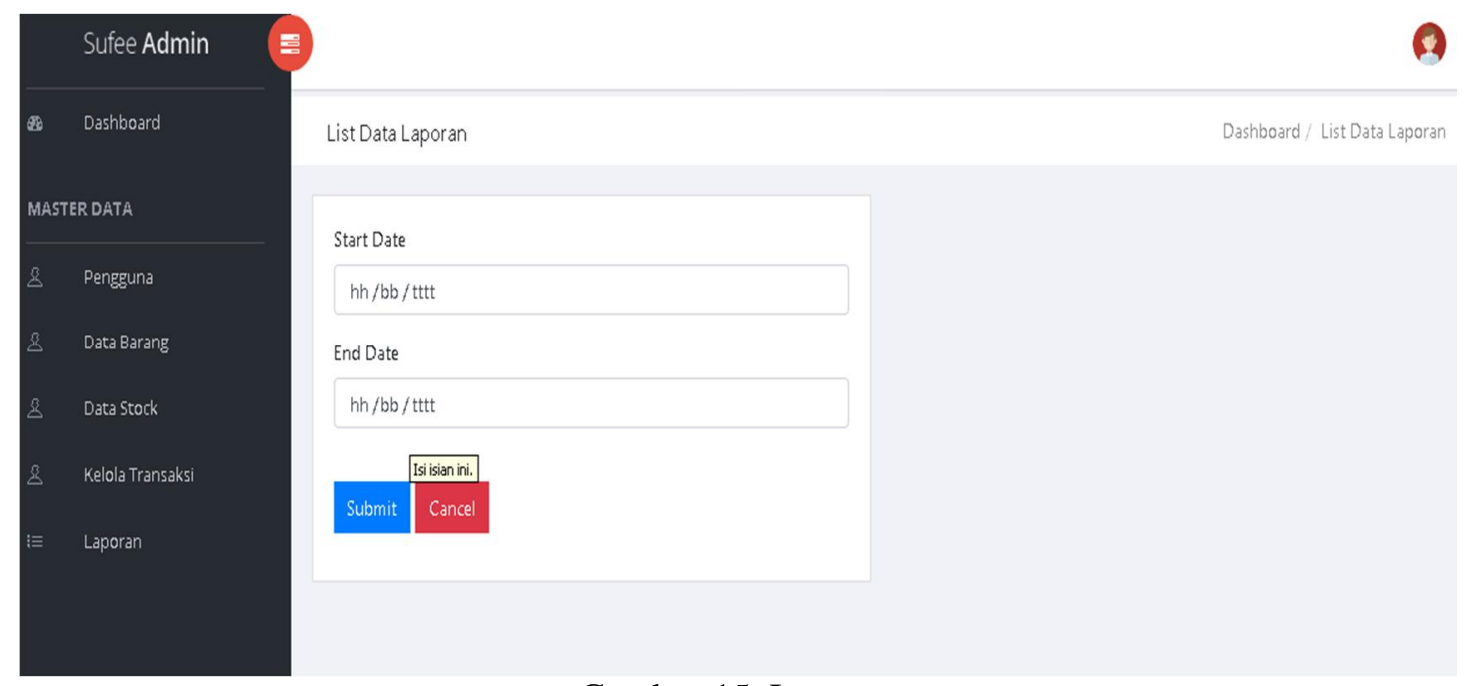

Gambar 15. Laporan

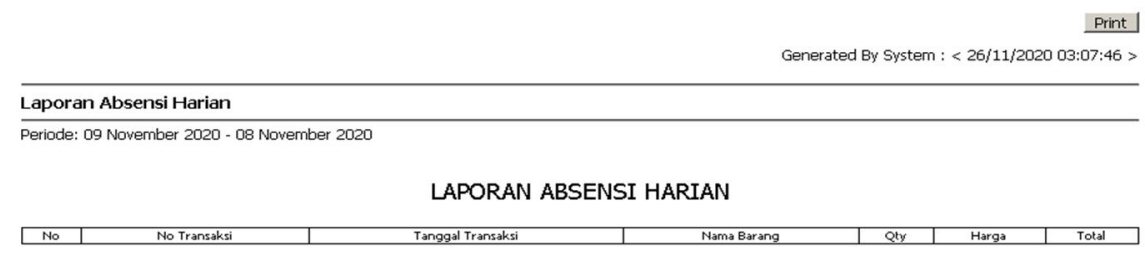

Gambar 2. Hasil Laporan

Ahmad, et.,al (Sistem Informasi Monitoring Penjualan Dan Prediksi Stok Barang Kios Pulsa Menggunakan Moving Average Berbasis Website) 
Implementasi Sistem Pemilik

1. Halaman Login

Halaman login merupakan halaman yang berfungsi untuk admin dalam melakukan login, admin terlebih dahulu memasukkan username dan password yang benar untuk dapat mengakses menu menu yang terdapat di dalamnya.

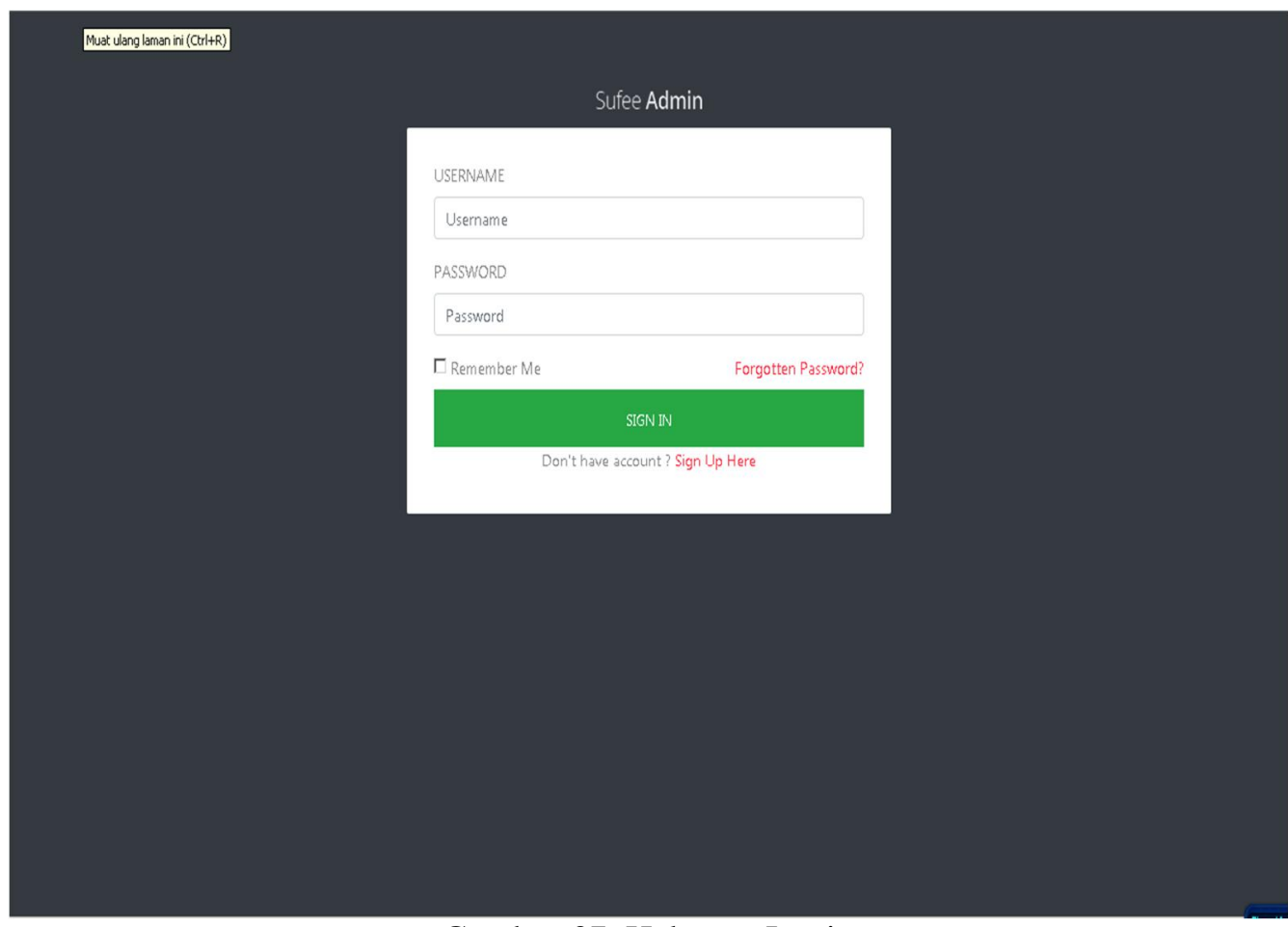

Gambar 37. Halaman Login

2. Halaman Dasboard

Halaman Dashboard adalah halaman awal setelah login atau menu utama

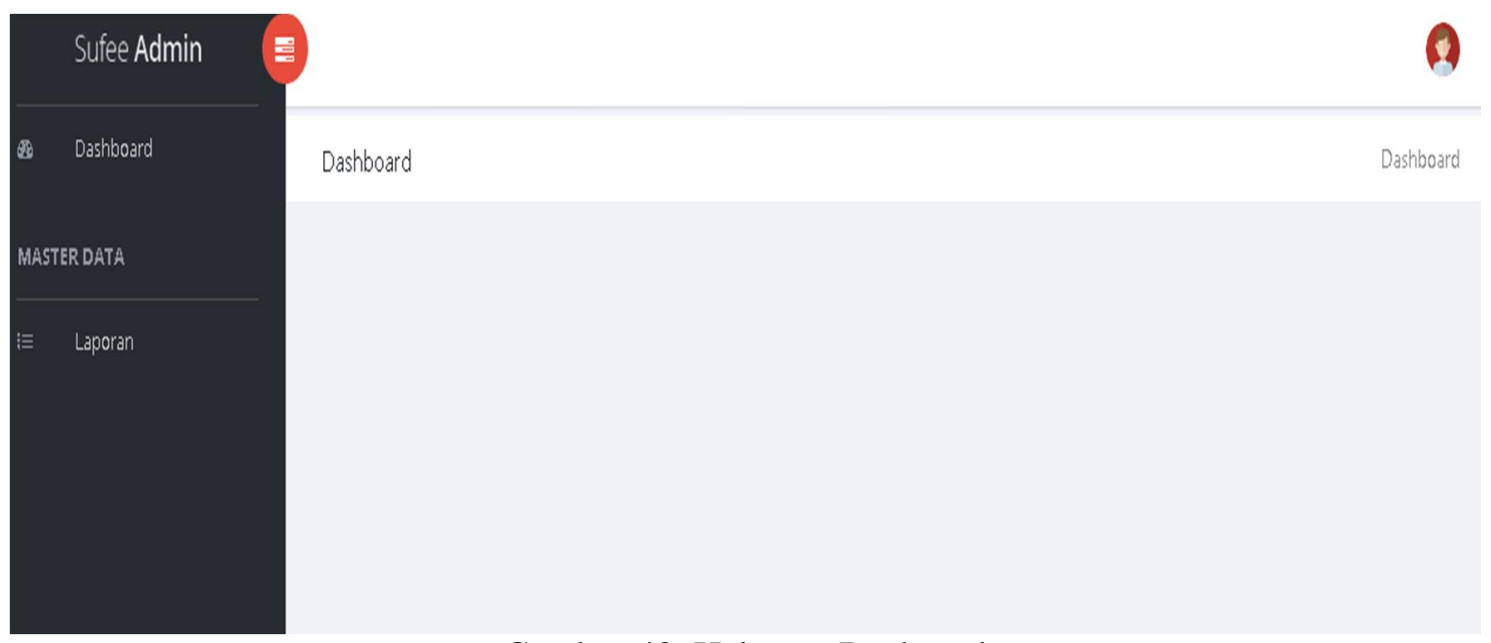

Gambar 48. Halaman Dasboard

Ahmad, et.,al (Sistem Informasi Monitoring Penjualan Dan Prediksi Stok Barang Kios Pulsa Menggunakan Moving Average Berbasis Website) 
3. Halaman Laporan

Halaman laporan berfungsi untuk menampilkan laporan dari penjualan

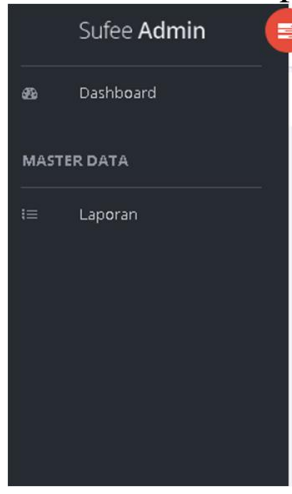

List Data Laporan

Start Date

hh/bb/tttt

End Date

hh $/ \mathrm{bb} / \mathrm{tttt}$

Gambar 58. Halaman Laporan

Pengujian Blackbox Testing (Isinya pengujian)

Pengujian yang dilakukan terhadap sistem yang dirancang adalah dengan pengujian black box seperti pada tabel berikut.

Tabel 1. Pengujian Blackbox Testing

\begin{tabular}{|c|c|c|c|c|}
\hline No & Halaman Uji & Cara Pengujian & Hasil yang Diharapkan & Status \\
\hline 1. & Halaman Login & $\begin{array}{l}\text { 1. Pengguna memasukan } \\
\text { username dan password }\end{array}$ & $\begin{array}{l}\text { Berhasil masuk kedalam } \\
\text { sistem }\end{array}$ & Sukses \\
\hline 2. & $\begin{array}{l}\text { Halaman } \\
\text { Dashboard }\end{array}$ & $\begin{array}{l}\text { 1. Pengguna membuka } \\
\text { halaman sistem }\end{array}$ & $\begin{array}{l}\text { Berhasil menampilkan } \\
\text { halaman dashboard }\end{array}$ & Sukses \\
\hline 3. & $\begin{array}{l}\text { Halaman } \\
\text { Pengguna }\end{array}$ & $\begin{array}{l}\text { 1. Buka menu data pengguna } \\
\text { 2. Melakukan penambahan } \\
\text { pengguna } \\
\text { 3. Melakukan edit pengguna } \\
\text { 4. Melakukan delete pengguna }\end{array}$ & $\begin{array}{l}\text { Berhasil menampilkan data } \\
\text { yang diminta }\end{array}$ & Sukses \\
\hline 4. & $\begin{array}{l}\text { Halaman data } \\
\text { barang }\end{array}$ & $\begin{array}{l}\text { 1. Buka menu data barang } \\
\text { 2. Melakukan penambahan } \\
\text { data barang } \\
\text { 3. Melakukan edit data barang } \\
\text { 4. Melakukan delete data } \\
\text { barang }\end{array}$ & $\begin{array}{l}\text { Berhasil menampilkan data } \\
\text { yang diminta }\end{array}$ & Sukses \\
\hline 5. & $\begin{array}{l}\text { Halaman } \\
\text { data stock }\end{array}$ & $\begin{array}{l}\text { 1. Buka Menu data stock } \\
\text { 2. Melakukan edit stock barang }\end{array}$ & $\begin{array}{l}\text { Berhasil menampilkan data } \\
\text { yang diminta }\end{array}$ & Sukses \\
\hline 6. & $\begin{array}{l}\text { Halaman } \\
\text { Transaksi }\end{array}$ & $\begin{array}{l}\text { 1. Membuka menu kelola } \\
\text { transaksi } \\
\text { 2. Melihat data transaksi } \\
\text { 3. menghapus data transaksi }\end{array}$ & $\begin{array}{l}\text { Berhasil Menampilkan data } \\
\text { yang diminta }\end{array}$ & Sukses \\
\hline 7. & $\begin{array}{l}\text { Halaman } \\
\text { Laporan }\end{array}$ & $\begin{array}{l}\text { 1. Dapat membuka Halaman } \\
\text { Laporan } \\
\text { 2. Dapat mensubmit laporan } \\
\text { dari tanggal tertentu } \\
\text { 3. Dapat menampilkan hasil } \\
\text { laporan }\end{array}$ & $\begin{array}{l}\text { Menampilkan data yang } \\
\text { diminta }\end{array}$ & Sukses \\
\hline
\end{tabular}

Ahmad, et.,al (Sistem Informasi Monitoring Penjualan Dan Prediksi Stok Barang Kios Pulsa Menggunakan Moving Average Berbasis Website) 
Metode Moving Average

Menghitung Batre Samsung tahun 2020

$$
M A=\frac{\sum 30}{3}=10
$$

Menghitung $M A$ kartu perdana tahun 2020

Menghitung $M A$ voucher pulsa tahun 2020

$$
M A=\frac{\sum 159}{3}=53
$$

$$
M A=\frac{\sum 273}{3}=91
$$

\section{KESIMPULAN DAN SARAN}

Pembuatan sistem informasi monitoring adalah untuk mempermudah dalam pengecekan stock barang, penghitungan untuk hasil rekap penjualan pulsa dan pemberian laporan kepada pemilik karena bisa diakses kapan pun dan dimanpun. Aplikasi prediksi stok barang dapat membantu pemilik kios dalam mengambil keputusan terhadap jumlah barang optimal yang akan dipesan ke supplier.

\section{UCAPAN TERIMA KASIH}

Penulis mengucapkan terima kasih yang setinggi-tingginya kepada pihak Universitas Nasional yang telah yg telah memberi dukungan financial terhadap penelitian ini

\section{DAFTAR PUSTAKA}

[1] Firman, A., Wowor, H. F., \& Najoan, X. 2016, Sistem Informasi Perpustakaan Online Berbasis Website.

[2] Hendini, A. 2016, Pemodelan Uml Sistem Informasi Monitoring Penjualan Dan Stok Barang (Studi Kasus: Distro Zhezha Pontianak).

[3] Hendini, A. 2016, Pemodelan UML Sistem Informasi Monitoring Penjualan dan Stok Barang (Studi Kasus: Distro Zhezha Pontianak).

[4] Lasminiasih, P, S., Akbar, A., Andriansyah, M., \& Utomo, R. B. 2016, Perancangan Sistem Informasi Kredit Mikro Mahasiswa Berbasis Web.

[5] Ramayasa, I. P., \& Ketut Surya Arnawa, I. B. 2015, Perancangan Sistem Monitoring Pengerjaan Skripsi pada STMIK Stikom Bali Berbasis Web.

[6] Sovia, R., \& Febio, J. 2017, Membangun Aplikasi E-Library Menggunakan Html, Php Script, dan MySQLDatabase. 